\title{
Disparate effects of endogenous and exogenous oestradiol on luteal phase function in women
}

\author{
I. E. Messinis* and A. A. Templeton \\ Department of Obstetrics and Gynaecology, University of Aberdeen, Foresterhill, \\ Aberdeen AB9 2ZD, U.K.
}

\begin{abstract}
Summary. Five normally ovulating women were induced to superovulate with pulsatile 'pure' FSH ( 28 i.u. every 3 h by a s.c. pump), and another 5 women were given an i.m. injection of $10 \mathrm{mg}$ oestradiol benzoate in the late follicular phase. Serum oestradiol concentrations in the luteal phase were similar in both groups and significantly higher than in corresponding control cycles. The luteal phase was of shorter duration in the FSH ( $11.2 \pm 0.7$ days) than in the control (13.4 \pm 0.2 days) and the oestrogentreatment cycles $(13.4 \pm 0.7$ days $)(P<0.05$, mean \pm s.e.m. $)$. FSH cycles had significantly lower early luteal serum LH (Day $1: 5.3 \pm 1.5 \mathrm{mi} . \mathrm{u} . / \mathrm{ml}$ ) and mid-luteal serum progesterone values $(35.4 \pm 3.5 \mathrm{nmol} / 1)$ compared with the control $(27.8 \pm$ $5.8 \mathrm{mi} . \mathrm{u} . / \mathrm{ml}$ and $65.4 \pm 5.7 \mathrm{nmol} / \mathrm{l}$, respectively) and oestrogen treatment cycles $(25.3 \pm 8.3 \mathrm{mi} . u$. $/ \mathrm{ml}$ and $59.1 \pm 8.4 \mathrm{nmol} / 1$, respectively $)(P<0.05$, mean \pm s.e.m. $)$. These results suggest that, in hyperstimulated cycles, the luteal phase can be disrupted even without follicle aspiration, and that suppression of endogenous LH secretion may be responsible.
\end{abstract}

\section{Introduction}

In spontaneous cycles of women there is debate as to whether the luteal phase after follicle aspiration is deficient, as compared to normal control cycles (Edwards et al., 1980b; Kerin et al., 1981; Garcia et al., 1981). In cycles induced with clomiphene for in-vitro fertilization (IVF), follicle aspiration does not appear to affect luteal function (Frydman et al., 1982), but several studies have shown that ovarian hyperstimulation with human gonadotrophins can result in shortening of the luteal phase and reduction of progesterone secretion (Edwards et al., 1980a; Quigley, 1984; Messinis et al., 1986a). There is therefore continuing doubt as to the occurrence and nature of the luteal effect and whether it is associated with follicle aspiration or with other factors related to multiple follicle development. Some studies have been designed to answer this question (Dlugi et al., 1984) but have been equivocal.

Messinis et al. (1986a) induced superovulation with clomiphene plus pulsatile hMG or FSH, and high serum oestradiol concentrations were achieved during the early luteal phase, and these showed inverse relationships with the duration of the luteal phase and pregnanediol excretion. Although these results suggest that oestradiol may be luteolytic in women, the mechanism is not clear.

The present study was designed (1) to investigate the characteristics of the luteal phase in cycles in which superovulation was induced with pulsatile 'pure' FSH and follicle aspiration did not take place, and (2) to examine the effect of exogenous oestrogen on luteal function in spontaneous cycles.

*Present address: Department of Obstetrics and Gynaecology, University of Ioannina, Ioannina, Greece. 


\section{Materials and Methods}

Patients. Ten normally menstruating women with long-standing infertility of unexplained origin were included. All volunteered for the study and gave informed consent. All had normal ovulatory cycles as assessed by basal body temperature, ultrasound scans of the ovaries and serum progesterone measurements before admission to the study. The women were randomly allocated into two groups.

The 5 women in Group 1 were studied in a spontaneous (control) and a treatment cycle. During the treatment cycle 'pure' FSH (Metrodin ampoules, each containing 75i.u. of molecularly engineered pure FSH without LH: Serono, Rome, Italy) was injected subcutaneously in a dose of 225 i.u. daily, given in a pulsatile manner ( $28 \mathrm{i}$.u. $/ 3 \mathrm{~h}$ ) via a pump delivering $70 \mu \mathrm{l}$ per pulse (Type MS 27; Graseby Medical, Watford, U.K.). In all 5 women the FSH infusion started on cycle Day 2 and stopped 24-30 h after the onset of the endogenous LH surge. The intention was to induce multiple follicular development and to increase the chance of conception. However, the possibility of multiple pregnancy was discussed with each woman and they were advised not to have intercourse if more than 2 follicles were about to ovulate, as assessed by ultrasound.

The other 5 women in Group 2 were studied in two spontaneous cycles. The first cycle was used as control. During the second cycle (treatment) an intramuscular injection of $10 \mathrm{mg}$ oestradiol benzoate (Benztrone ampoules; Paines and Byrne Ltd, Middlesex, U.K.) was given to the women. The intention was to inject the oestradiol benzoate as close as possible to the time of the onset of the endogenous LH surge. The information was obtained from the control cycle and was based on both ultrasonic size of the dominant follicle and serum oestradiol-17 $\beta$ concentrations. The time (mean \pm s.e.m.) between the oestradiol benzoate injection and the onset of the LH surge was $19 \cdot 2 \pm 7 \cdot 1 \mathrm{~h}$ (range $642 \mathrm{~h}$ ).

All women in both groups had an endogenous LH surge, which was characterized in 6-h blood samples, in both the control and treatment cycle. Ovulation after the LH surge was confirmed by ultrasound (collapse of dominant follicles) in all control and oestrogen treatment cycles and in all but one of the FSH treatment cycles. Two women during the FSH cycle had multiple ovulations. None of the women became pregnant. In all cycles blood samples were taken daily from the day of ovulation which was considered as Day 1 of the luteal phase, until menstruation. After centrifugation serum was stored at $-20^{\circ} \mathrm{C}$ for subsequent measurement of $\mathrm{LH}$, oestradiol, progesterone and prolactin concentrations.

Hormone assays. Measurement of LH in serum was done by a double radioimmunoassay using kits purchased from Amersham International plc, Bucks, U.K. (Amerlex LH RIA kit). The results are expressed as mi.u. standards of human pituitary LH (1st IRP 68/40)/ml. Oestradiol was measured in serum using a radioimmunoassay kit purchased from CIS (Torino, Italy). Values are expressed as pmol/l. The cross-reaction of the antiserum used with oestrone, oestriol and synthetic oestradiol compounds was $<1 \%$, in agreement with previous data (Oriowo et al., 1980). Measurement of progesterone in serum was done using the Amerlex-M Progesterone RIA kit (Amersham International plc) and results are expressed as nmol/l. Prolactin was measured in blood by a double radioimmunoassay using kits purchased from Amersham International plc (Prolactin RIA kit). Results are expressed in $\mu$ i.u./ml (WHO 1st IRP 75/504). The lower limits of detection for LH, oestradiol, progesterone and prolactin were $1.8 \mathrm{mi} . \mathrm{u} . / \mathrm{ml}, 90 \mathrm{pmol} / 1,1.3 \mathrm{nmol} / 1$ and $95 \mu$ i.u. $/ \mathrm{ml}$ respectively, while interassay and intra-assay coefficients of variation were 8.6 and $5 \cdot 4 \%, 9 \cdot 8$ and $7 \cdot 6 \%, 6$ and $10.9 \%$, and $8 \cdot 1$ and $8 \cdot 2 \%$, respectively.

Statistical Analysis. Statistical evaluation of the results was done by Student's $t$ test and two-way analysis of variance (ANOVA).

\section{Results}

During FSH infusion multiple follicular development was stimulated. The mean ( \pm s.e.m.) number of follicles $\geq 12 \mathrm{~mm}$ and $\geq 15 \mathrm{~mm}$ on the day of onset of the LH surge, as assessed by ultrasound, was $4.2 \pm 0.8$ and $2.4 \pm 0.5$ respectively. On Day 2 of the luteal phase, the total number (mean \pm s.e.m.) of unovulated and small follicles $(12-15 \mathrm{~mm}$ ) was $3.0 \pm 0.8$. In all control and oestrogen treatment cycles, only one dominant follicle developed. LH concentrations during the follicular phase did not differ significantly between the FSH treatment and the corresponding control cycles (by ANOVA), although they were lower in the FSH cycles during the last 3 days before the onset of the LH surge (cycle Day 7: $5.5 \pm 0.8$ and $7.6 \pm 0.6 \mathrm{mi} . \mathrm{u} . / \mathrm{ml}$ respectively). The endogenous $\mathrm{LH}$ surge was markedly attenuated, both in duration and peak levels in 4 of the FSH cycles, as compared to control cycles, while in the oestrogen cycles the characteristics of the LH surge were similar to those in the control cycles. The cycle day on which the LH surge started did not differ significantly between the control and the oestrogen cycles. However, in the FSH cycles both the onset and the peak of the $\mathrm{LH}$ surge were 3 days earlier on average than in the control cycles (Messinis \& Templeton, 1986). 
(a)
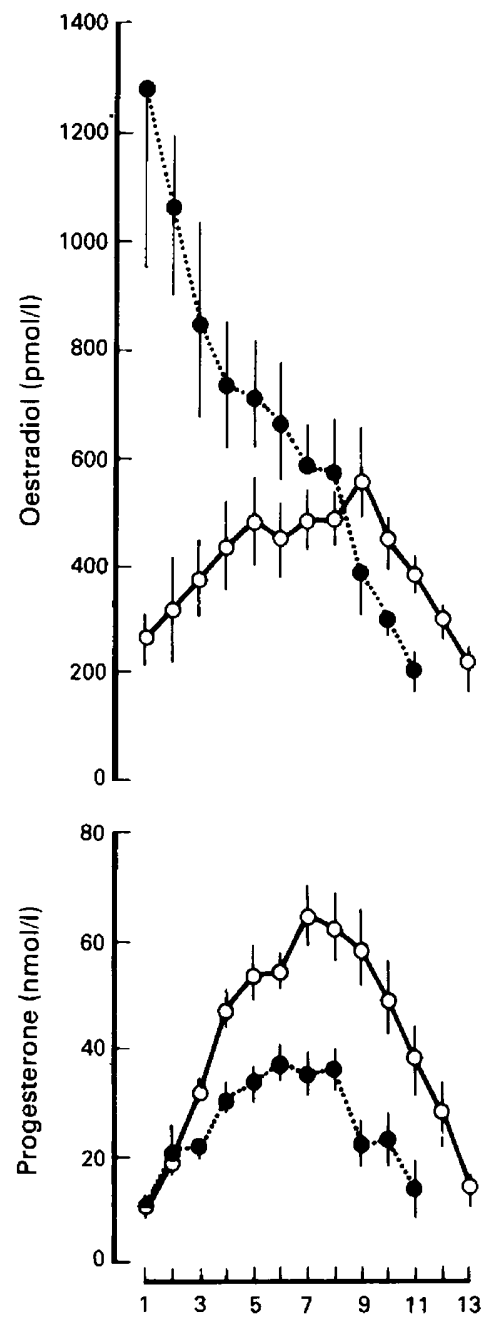

(b)
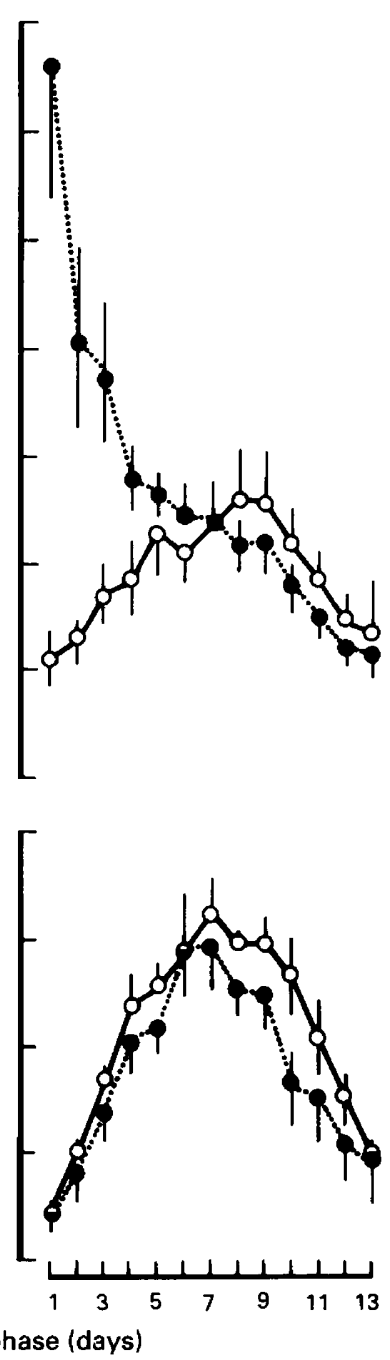

Fig. 1. Serum oestradiol and progesterone concentrations during the luteal phase of cycles of (a) untreated (control, $\mathrm{O}-\mathrm{O}$ ) and FSH-treated $\left(\mathbf{O}_{---}\right)$) women and (b) untreated (control, $\bigcirc-\bigcirc)$ and oestrogen-treated $(---)$ women (oestradiol benzoate $(10 \mathrm{mg})$ was injected i.m. 6-42 $\mathrm{h}$ before the onset of the endogenous LH surge). Values are mean \pm s.e.m. for 5 women in (a) except for Days 10 and 11 for the FSH cycles for which $\mathrm{N}=4$, and for 5 women in (b) except for Days 12 and 13 in the oestrogen cycles for which $\mathrm{N}=3$.

The duration of the luteal phase (mean \pm s.e.m.) in the FSH treatment cycles $(11 \cdot 2 \pm 0 \cdot 7$, range 9-14 days) was significantly shorter than in the corresponding control cycles $(13 \cdot 4 \pm 0 \cdot 2$, range 13-14 cays) $(P<0.05$, paired $t$ test), but did not differ significantly between the oestrogen treatment (13.4 \pm 0.7 , range 12-16, days) and the control cycles (13.6 \pm 0.3 , range 13-15, days). The duration of the luteal phase was longer than 11 days in only 1 of the 5 FSH treatment cycles.

Figure l(a) shows serum oestradiol and progesterone concentrations (mean \pm s.e.m.) in Group 1 women. In the FSH treatment cycles, serum oestradiol values during the first half of the luteal phase (Day 1: $1292 \pm 348 \mathrm{pmol} / \mathrm{l}$ ) were significantly higher than in the control cycles (Day 1: 


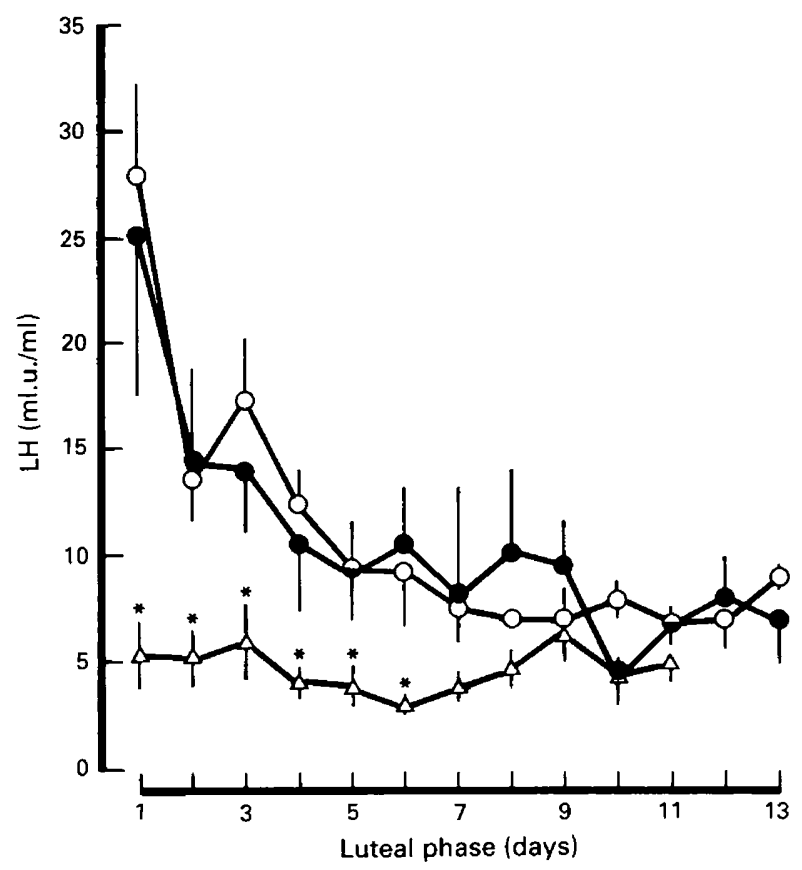

Fig. 2. Serum LH concentrations during the luteal phase of untreated (control $(O)(N=10)$, FSH superovulated $(\triangle)(N=5)$ and oestrogen-treatment cycles $(\Theta)(N=5)$ in normally ovulating women. Oestradiol benzoate was injected intramuscularly $(10 \mathrm{mg}) 6-42 \mathrm{~h}$ before the onset of the endogenous LH surge. At each point results are mean ( \pm s.e.m.) of 5 samples except on Days 12 and 13 in the oestrogen treatment cycles ( 3 samples) and Days 10 and 11 in the FSH cycles (4 samples). ${ }^{*} P<0.05$ (compared to control and oestrogen treatment cycles).

$260 \pm 45 \mathrm{pmol} / 1, \mathrm{~F}_{6,24}=3.0, P<0.05$ by ANOVA). Then oestradiol concentrations in the treatment cycles decreased progressively until the end of the cycle, in contrast to the control cycles in which serum oestradiol values increased significantly, reaching a peak on Day $9(572 \pm 83 \mathrm{pmol} / \mathrm{l})$ $(P<0.01$, paired $t$ test) before decreasing until menstruation. Serum progesterone concentrations on Day 1 of the luteal phase did not differ significantly between the control and the FSH treatment cycles $(9.4 \pm 1.6$ and $11.2 \pm 1.4 \mathrm{nmol} / 1$ respectively). Then progesterone concentrations in the control cycles increased more rapidly and remained significantly higher than in the FSH treatment cycles until the end of the luteal phase (peak levels on Day 7:65.4 \pm 5.7 and $35.4 \pm 3.5 \mathrm{nmol} / \mathrm{l}$, respectively; $\mathrm{F}_{12,48}=8.9, P<0.01$, by ANOVA). This pattern of serum progesterone change during the luteal phase was seen in all 5 FSH treatment cycles, as compared to the corresponding control cycles.

There were no significant differences in serum prolactin concentrations between the FSH and the control cycles throughout the luteal phase.

Figure 1(b) shows serum oestradiol and progesterone concentrations in Group 2 women. Oestradiol values were significantly higher during the first half of the luteal phase in the oestrogen cycles (Day 1: $1322 \pm 250 \mathrm{pmol} / \mathrm{l}$ ) than in the corresponding control cycles (Day 1: $222 \pm$ $56 \mathrm{pmol} / 1 ; \mathrm{F}_{4,16}=10 \cdot 2, P<0 \cdot 01$, by ANOVA). Then, serum oestradiol in the oestrogen cycles decreased progressively until the end of the luteal phase. In contrast to this, serum oestradiol concentrations in the control cycles increased significantly and reached a peak on Day 8 $(528 \pm 89 \mathrm{pmol} / \mathrm{l})(P<0.001$, paired $t$ test $)$, decreasing progressively thereafter until menstruation. Serum progesterone levels did not differ significantly between the control and the oestrogen cycles 
throughout the luteal phase. Peak progesterone values were achieved in both cycles on Day 7 of the luteal phase $(65 \cdot 5 \pm 6 \cdot 9$ and $59 \cdot 1 \pm 8 \cdot 4 \mathrm{nmol} / 1$, respectively).

Mean ( \pm s.e.m.) serum oestradiol concentrations in the FSH treatment cycles of the first group and in the oestrogen cycles of the second group followed the same pattern of decline throughout the luteal phase and did not differ significantly between the two groups at any point (Fig. 1).

Figure 2 shows serum LH concentrations during the luteal phase in the FSH treatment cycles, the oestrogen cycles and the control cycles. All 10 control cycles were combined since there was no significant difference between the two groups of women throughout the luteal phase (by ANOVA). Serum LH concentrations were significantly higher in the oestrogen and the control cycles than in the FSH cycles from Day $1(25 \cdot 3 \pm 8.3,27 \cdot 8 \pm 5.8$ and $5.3 \pm 1.5 \mathrm{mi} . \mathrm{u} . / \mathrm{ml}$, respectively) to Day 6 of the luteal phase $(10.6 \pm 2 \cdot 7,9.0 \pm 3.3$ and $2.6 \pm 0.3 \mathrm{mi} . \mathrm{u} . / \mathrm{ml}$, respectively $)(P<0.05)$. Thereafter LH concentrations did not differ significantly among the three groups.

\section{Discussion}

This study shows that, in women stimulated with pulsatile FSH, a shortening of the luteal phase and reduction of progesterone secretion can occur, as compared to spontaneous cycles. This suggests a degree of disruption of the luteal phase even without follicle aspiration, and appears to be related to the presence of multiple follicles.

In agreement with our previous results (Messinis et al., 1986a), cycles stimulated with FSH had high serum oestradiol concentrations in the first half of the luteal phase. However, in the present study, high serum oestradiol values in the early luteal phase of spontaneous cycles were not luteolytic. These results suggest that either oestradiol has a luteolytic effect at its site of ovarian production (Karsch \& Sutton, 1976) or in spontaneous cycles the newly formed human corpus luteum is refractory to the luteolytic effect of high oestradiol concentrations (Johansson \& Gemzell, 1971; Schoonmaker et al., 1981).

Previous studies in women and monkeys have shown the importance of pituitary LH secretion after ovulation for the maintenance of corpus luteum function (Vande Wiele et al., 1970; Hutchison \& Zeleznik, 1984). In the present study, the low serum LH concentrations during the first half of the luteal phase in the FSH, as compared to control, cycles indicate that in these cycles endogenous $\mathrm{LH}$ secretion was significantly suppressed not only during the LH surge (Messinis et al., 1985, 1986b) but also after ovulation. The accompanying defect in corpus luteum function in the FSH cycles suggests that LH secretion needs to be maintained at an appropriate level throughout the whole luteal phase if normal function is to be achieved.

Whether the degree of luteal phase disruption seen in the present study can decrease the likelihood of establishing pregnancies is not known. Luteal deficiency has also been reported in hyperstimulated cycles in which ovulation was induced with hCG (Quigley, 1984), but the optimal dose of mid-cycle hCG which would be adequate to support normal luteal function in hyperstimulated cycles is not known. Previous studies have shown higher pregnancy rates when hCG is given in multiple injections during the luteal phase in cycles after embryo transfer (O'Neill et al., 1985), as well as in cycles induced with human gonadotrophins in anovulatory women (Brown, 1978; Messinis \& Nillius, 1981).

The present results do, however, exclude the possibility that the alterations in luteal-phase function seen in the FSH stimulated cycles were due to hyperprolactinaemia (Andrews, 1979).

In conclusion, the present study shows that, in women hyperstimulated with pulsatile 'pure' FSH, luteal function can be disrupted even without follicle aspiration. In spontaneous cycles, high serum oestradiol concentrations in the early luteal phase was not luteolytic. It is suggested that in hyperstimulated cycles suppression of endogenous LH secretion early in the luteal phase is responsible for the disruption of the luteal phase. 
We thank Professor Arnold Klopper for help in recruiting the volunteers and $\mathrm{Mr}$ Robert Duncan and the staff of the Reproductive Endocrine Laboratories for the hormone assays.

\section{References}

Andrews, W.C. (1979) Luteal phase defects. Fert. Steril. 32, 501-509.

Brown, J.B. (1978) Pituitary control of ovarian functionconcepts derived from gonadotrophin therapy. Aust. N.Z. Jl Obstet. Gynaec. 18, 47-54.

Dlugi, A.M., Laufer, N., De Cherney, A.H., MacLusky, N.J., Haseltine, F.P., Polan, M.L., Mezer, H.C., Tarlatzis, B. \& Naftolin, F. (1984) The periovulatory and luteal phase of conception cycles following in vitro fertilization and embryo transfer. Fert. Steril. 41, 530-537.

Edwards, R.G., Steptoe, P.C. \& Purdy, J.M. (1980a) Establishing full term human pregnancies using cleaving embryos grown in vitro. Br. J. Obstet. Gynaecol. 87, 737-756.

Edwards, R.G., Steptoe, P.C., Fowler, R.E. \& Baillie, J. (1980b) Observations on preovulatory human ovar. ian follicles and their aspirates. Br. J. Obstet. Gynaecol. 87, 769-779.

Frydman, R., Testart, J., Giacomini, P., Imbert, M.C., Martin, E. \& Nahoul, K. (1982) Hormonal and histological study of the luteal phase in women following aspiration of the preovulatory follicle. Fert. Steril. 38, 312-317.

Garcia, J., Jones, G.S., Acosta, A.A. \& Wright, G.L. (1981) Corpus iuteum function after follicle aspiration for oocyte retrieval. Fert. Steril. 36, 565-572.

Hutchison, J.S. \& Zeleznik, A.J. (1984) The rhesus monkey corpus luteum is dependent on pituitary gonadotropin secretion throughout the luteal phase of the menstrual cycle. Endocrinology 115, $1780-1786$.

Johansson, D.B. \& Gemzell, C. (1971) Plasma levels of progesterone during the luteal phase in normal women treated with synthetic oestrogens (RS 2874, F 6103 and ethinyloestradiol). Acta endocr., Copenh. 68, 551-560.

Karsch, F.J. \& Sutton, G.P. (1976) An intra-ovarian site for the luteolytic action of estrogen in the rhesus monkey. Endocrinology 98, 553-561.

Kerin, J.F., Broom, T.J., Ralph, M.M., Edmonds, D.K., Warner, G.M., Jeffrey, R., Crocker, J.M., Godfrey, B., Cox, L.W., Seamark, R.F. \& Matthews, C.D. (1981) Human luteal phase function following oocyte aspiration from the immediately preovular graafian follicle of spontaneous ovular cycles. Br. J. Obstet. Gynaecol. 88, 1021-1028.
Messinis, I.E. \& Nillius, S.J. (1981) Human gonadotrophin therapy of anovulatory infertility. Five-year results. Acta endocr., Copenh., Suppl. 243, Abstr. 200.

Messinis, I.E. \& Templeton, A. (1986) The effect of pulsatile follicle stimulating hormone on the endogenous luteinizing hormone surge in women. Clin. Endocr. (in press).

Messinis, I.E., Templeton, A. \& Baird, D.T. (1985) Endogenous luteinizing hormone surge during superovulation induction with sequential use of clomiphene citrate and pulsatile human menopausal gonadotropin. J. clin. Endocr. Metab. 61, 1076-1080.

Messinis, I.E., Templeton, A. \& Baird, D.T. (1986a) Luteal phase following ovarian hyperstimulation. $\mathrm{Br}$. J. Obstet. Gynaecol. (in press).

Messinis, I.E., Templeton, A. \& Baird, D.T. (1986b) Endogenous luteinizing hormone surge in women during induction of multiple follicular development with pulsatile follicle stimulating hormone. Clin. Endocr. 24, 193-201.

O'Neill, C., Ferrier, A.J., Vaughan, J., Sinosich, M.J. \& Saunders, D.M. (1985) Causes of implantation failure after in vitro fertilisation and embryo transfer. Lancet 2, 615 .

Oriowo, M.A., Landgren, B-M., Strenström, B. \& Diczfalusy, E. (1980) A comparison of the pharmacokinetic properties of three estradiol esters. Contraception 21, 415-424.

Quigley, M.M. (1984) The use of ovulation-inducing agents in in vitro fertilization. Clin. Obstet. Gynaecol. 27, 983-992.

Schoonmaker, J.N., Victery, W. \& Karcsh, F.J. (1981) A receptive period for estradiol-induced luteolysis in the rhesus monkey. Endocrinology 108, 1874-1877.

Vande Wiele, R.L., Bogumil, J., Dyrenfurth, I., Ferin, M., Jewelewicz, R., Warren, M., Rizkallah, T. \& Mikhail, G. (1970) Mechanisms regulating the menstrual cycle in women. Recent Prog. Horm. Res. 26, 63-103. 